\title{
SCIENTIFIC EPONYM IN EDUCATIONAL UNIVERSE
}

\author{
Uladzimir Slabin \\ University of Oregon, USA
}

We, the educators, are born into the educational Universe. Real and educational Universes we live in have amazingly much in common. They can be juxtaposed using numerous physical and chemical analogies, beginning with the most basic structural elements (Table 1).

\section{Table 1. Resemblance between components of real and educational Universes.}

Being material, real Universe consists of two sorts of matter: substance and field.
Being ideal (imagined), educational Universe consists of two sorts of ideal stuff: expertise and educational conception.

\footnotetext{
Field (gravitational or electromagnetic):

- is created by substance

- (mass and/or charge);

- impacts substance: makes it attract (mass anyway, opposite charges) or repel (like charges);

- is energetically characterized by field strength (e.g. V/m for electric, acceleration due to gravity for gravitational);

- the field strength determines vector (force and direction) of how fast and where the mass or charge moves.

Substance can interconvert: proton into neutron, electron and positron
into photons.
}

Educational conception as a field:

- is created by publicly accumulated expertise (knowledge and/or ignorance);

- impacts expertise: makes it be taught or excluded (postponed) from teaching;

- is ideologically characterized by didactic principles (e.g. humanization and historicism);

- the principles determine vector (content, forms, methods, techniques) of teaching - how fast and where the expertise moves.

Expertise can interconvert: in organized pedagogical process ignorance goes into knowledge.

Ignorance and knowledge attract to form an expertise set for each object (ignorance-and-knowledge).

Ignorance locates in the core of cognition, being its motive force. Knowledge coats the ignorance as the shell. As of today, the knowledge has been researched on better than the ignorance.

Protons locate in the atomic nucleus, electrons in the shell. As today, the shell has been researched on better than the nucleus.

Both ignorance and knowledge have levels. E.g. for knowledge there are data - information - knowledge - wisdom.

Both atomic nucleus and shell have levels and sublevels inside. E.g. for shell there are K-, L-, M-, N- levels with s-, p-, d-, f- asf. sublevels.

Similar atoms constitute the element.

Elements are grouped into metals, nonmetals and metalloids.

Ignorance and knowledge about a particular object constitute the knowledge element.

Knowledge elements can be grouped into those describing people and things.

Strictly speaking, knowledge for every object in educational Universe is limited by ignorance or, in other words, these two components co-exist. However, pedagogy primarily deals with knowledge, its acquisition and 
retention. It ignores the ignorance, leaving it as a subject for a more generic science of psychology. Similarly, atomic nuclei in real Universe are a subject for a more generic science of physics, being only slightly studied in chemistry. To research on knowledge is by far easier than on ignorance, same as chemical research involving mere electron shells is easier than physical research targeting atomic nuclei.

With respect to science education, let us limit 'people' in this context to scientists. It is also worth to limit 'things' to loosely defined big and small discoveries - objects the scientists produce or work with (theories, laws, reactions, principles, rules, equations, constants, chemicals, solutions, flasks, adapters, condensers, asf.). One can even outline a periodic system of knowledge elements, certainly, not in details because scientists and discoveries many times outnumber discovered chemical elements. Like metals and nonmetals occupy the lower left and the upper right areas, resp., scientists and discoveries would have their distribution in such table.

Having addressed the educational Universe's primary hierarchy and identified the two families of knowledge elements, one should further consider organization of these elements (Table 2).

Table 2. Resemblance between chemical elements and knowledge elements.

Particular metal and non-metal elements form mixtures and binary compounds in physical and chemical processes:

- metal-metal alloys (steel, brass) and intermetallides (Nb3Sn);

- nonmetal-nonmetal, e.g. water $(\mathrm{H} 2 \mathrm{O})$, ammonia $(\mathrm{NH} 3)$, methane $(\mathrm{CH} 4)$, carbon dioxide (CO2);

- metal-nonmetal, e.g. oxides $(\mathrm{CaO})$, phosphides (Zn3P2), salts (NaCl).
Particular knowledge about scientist and knowledge about discovery form binary compounds in social, causal, and linguistic processes, resp.

- scientist-scientist, e.g. rivalry (Thomas Edison and Nikola Tesla), teacher-student partnership (Nikolai Zinin and Alexander Butlerov) or marriage (Marie Skłodowska and Pierre Curie):

- discovery-discovery, i.e. relations and operations between theory and equation, task and solution, procedures and calculations, samples and techniques, etc.

- scientist-discovery, e.g. story of discovery (oxygen by John Priestley, electromagnetism by Michael Faraday) or eponym (Boyle law, Le Châtelier principle, Planck constant, Claisen flask).

In today's practice of science education, teachers spend the most of available classroom or auditorium time to teach the discovery-discovery (thing-thing) compounds. The scientist-scientist and scientist-discovery compounds are addressed a way less frequently. However, the aforementioned principles of humanization and historicism, whether manifested explicitly or present implicitly in national standards, determine the field in the educational Universe. This field implies scientists being taught together with their discoveries. Hence the importance of scientific eponym, aka named notion - a natural linguistic compound of scientist and his/her discovery in scientific and historical context. With respect to educational goals, eponyms can and should be unwrapped into stories of discovery.

Using analogy with the real Universe and chemical VB (Valence Bond) and MO (Molecular Orbitals are Linear Combination of Atomic Orbitals) theories, consider how eponyms are formed in educational Universe (Fig. 1 and 2). One should remark that formation of a widely adopted scientific eponym is a complex process being a subject for sociology of science. It involves a great deal more factors than just knowledge about scientist and his discovery. Moreover, this process can be reversible. Nevertheless, the analogy is curious - it looks like formation of chemical bonds and formation of eponyms obey pretty similar logic (Table 3 ).
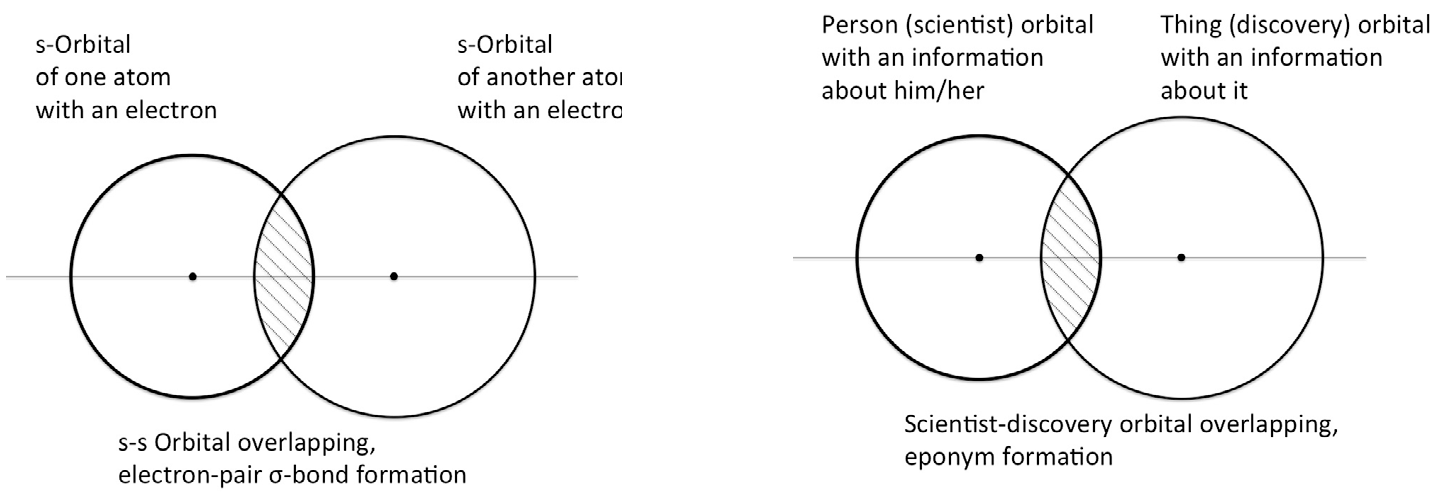

Figure 1: Formation of an eponym (right) as a VB metaphor of chemical bond (left). 

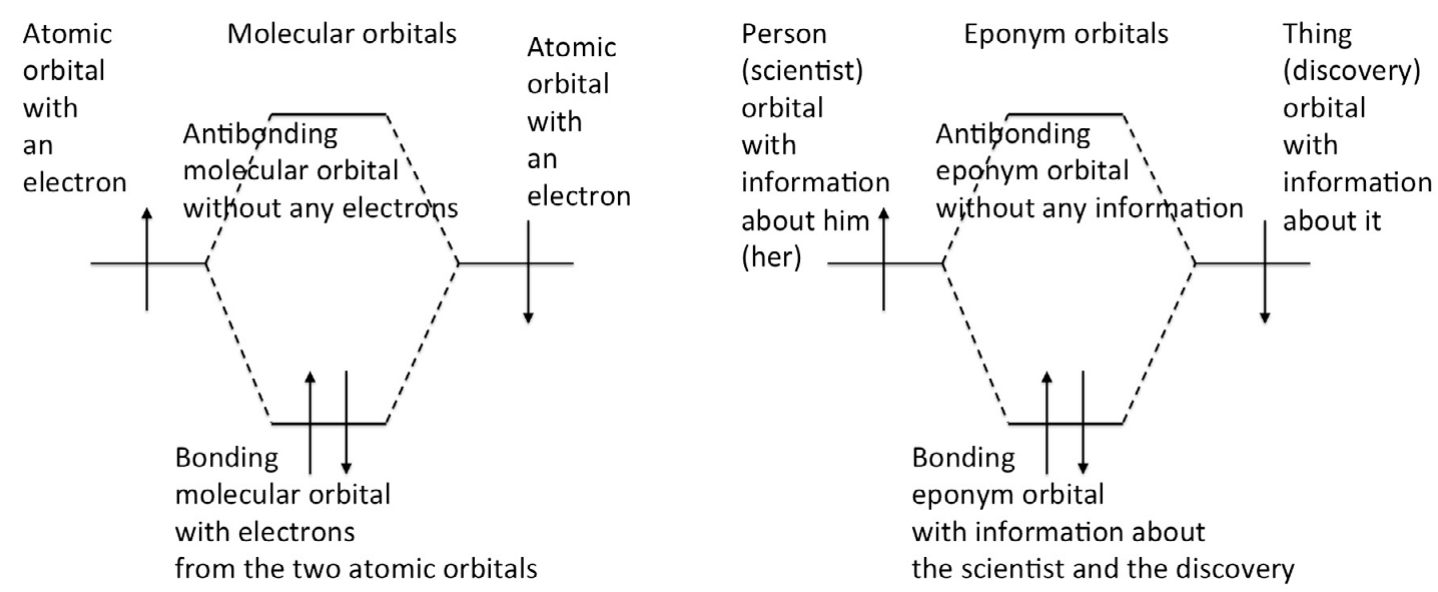

Figure 2: Formation of an eponym (right) as a MO metaphor of chemical bond (left).

\section{Table 3. Resemblance between formation of molecule and formation of eponym in the light of VB and MO} theories.

\begin{tabular}{|c|c|}
\hline $\begin{array}{l}\text { Atoms in molecules are held together due to paired } \\
\text { electrons. }\end{array}$ & $\begin{array}{l}\text { Knowledge about scientist and his/her discovery is held together due to combining relevant } \\
\text { information about both components. }\end{array}$ \\
\hline $\begin{array}{l}\text { Only external (valence) electrons from outer levels } \\
\text { participate in the bond formation. } \\
\text { Inner electrons remain do not engage. }\end{array}$ & $\begin{array}{l}\text { Only external (in terms of science education), most relevant info about scientist is used to } \\
\text { form an eponym. } \\
\text { Information of scientist's non-scientific biography, political views, hobbies, private affairs is } \\
\text { not involved. }\end{array}$ \\
\hline $\begin{array}{l}\text { Atomic orbitals can combine to form bonding molecular } \\
\text { orbital(s): } \\
\text { - stability of the system increases; } \\
\text { - energy of the system lowers. }\end{array}$ & $\begin{array}{l}\text { Information about scientist and discovery is relevant, appropriate, engaging and/or } \\
\text { conveyed in such a way that the whole combination is remembered more reliably than sci- } \\
\text { entist's name and the discovery's description apart. Interesting and catchy. It is an eponym! } \\
\text { - stability of two-word system increases; } \\
\text { - energy to memorize and retain lowers. }\end{array}$ \\
\hline $\begin{array}{l}\text { Atomic orbitals can combine to form anti-bonding } \\
\text { molecular orbital(s): } \\
\text { - stability of the system decreases; } \\
\text { - energy of the system increases. }\end{array}$ & $\begin{array}{l}\text { Information about scientist and discovery is irrelevant, boring, freaking out and/or conveyed } \\
\text { in such a way that the whole combination is remembered less reliably than scientist's name } \\
\text { and the discovery's description apart. Easy forgettable. } \\
\text { - stability of two-word system decreases; } \\
\text { - energy to memorize and retain the two-word system increases. }\end{array}$ \\
\hline $\begin{array}{l}\text { Atomic orbitals can combine to form non-bonding } \\
\text { molecular orbital: stability and energy of the system } \\
\text { does not change. }\end{array}$ & $\begin{array}{l}\text { When information about scientist and discovery and/or teaching technique is inconsist- } \\
\text { ent, positive impact is nullified by negative. No notable difference in retention of the whole } \\
\text { combination in comparison to the two words set apart. }\end{array}$ \\
\hline $\begin{array}{l}\text { Electrons can jump from bonding to anti-bonding } \\
\text { molecular orbital, which results in the bond breakage. }\end{array}$ & $\begin{array}{l}\text { When information about scientist and discovery in an existing eponym can be found } \\
\text { unethical, imprecise or inappropriate - eponym disappears (e.g. abandonment of eponyms } \\
\text { featuring Nazi scientists). }\end{array}$ \\
\hline $\begin{array}{l}\text { Along with known stable compounds, chemist can syn- } \\
\text { thesize unstable but theoretically allowed compounds. }\end{array}$ & $\begin{array}{l}\text { Along with existing official eponyms, educator can make up situational, temporary eponyms } \\
\text { to use in classroom or auditorium if they are in line with the principles of humanization and } \\
\text { historicism and allowed by teaching freedom. }\end{array}$ \\
\hline
\end{tabular}

The following IUPAC-nomenclatural parallels demonstrate that scientific eponyms in educational Universe are manipulated like chemical compounds in the real. Moreover, eponyms can undergo changes like chemicals, engaging in linguistic "reactions": 
ISSN 1648-3898/Print/

ISSN 2538-7138/Online/

Table 4. Resemblance between nomenclature and transformations of chemical eponyms and chemical compounds.

\begin{tabular}{|c|c|}
\hline $\begin{array}{l}\text { Compound - sodium chloride: } \\
\text { - metal cation: sodium } \mathrm{Na}^{+} \text {; } \\
\text { - nonmetal anion: chloride } \mathrm{Cl}^{-}\end{array}$ & $\begin{array}{l}\text { Eponym - Claisen reaction: } \\
\text { - scientist: Claisen; } \\
\text { - discovery: reaction }\end{array}$ \\
\hline $\begin{array}{l}\text { The cation can combine with some other anions: } \\
\text { - sodium sulfide; sodium oxide }\end{array}$ & $\begin{array}{l}\text { The scientist can author several other discoveries: } \\
\text { - Claisen flask; Claisen adapter; Claisen condensation }\end{array}$ \\
\hline $\begin{array}{l}\text { The anion can combine with some other cations: } \\
\text { - potassium chloride; iron (III) chloride }\end{array}$ & $\begin{array}{l}\text { This type of discovery can be made by different scientists: } \\
\text { - Grignard reaction; Wittig reaction; Tishchenko reaction; Sabatier reaction; Cannizzaro } \\
\text { reaction }\end{array}$ \\
\hline $\begin{array}{l}\text { The anion sometimes can be present in binary mixtures } \\
\text { or double salts: } \\
\text { - potassium sodium chloride (sylvinite) } \mathrm{KCl} \cdot \mathrm{NaCl}\end{array}$ & $\begin{array}{l}\text { The discovery sometimes can have multiple authors: } \\
\text { - Claisen-Wislicenus reaction; Claisen-Schmidt reaction; Claisen-Geuther reaction }\end{array}$ \\
\hline $\begin{array}{l}\text { Compounds can change or react with other compounds in } \\
\text { the following chemical reactions: } \\
\text { - synthesis: zinc + phosphorus } \rightarrow \text { zinc phosphide; } \\
\text { - decomposition: mercury (II) oxide } \rightarrow \text { mercury + oxygen; } \\
\text { - single displacement: iron + copper (II) bromide } \rightarrow \text { iron } \\
\text { (II) bromide + copper; } \\
\text { - double displacement: silver nitrate + potassium iodide } \\
\rightarrow \text { silver iodide + potassium nitrate }\end{array}$ & $\begin{array}{l}\text { Eponyms can change or interact with other eponyms in the following linguistic transfor- } \\
\text { mations: } \\
\text { - synthesis: Boyle + law } \rightarrow \text { Boyle law; } \\
\text { - decomposition: Mendeleev periodic table } \rightarrow \text { Mendeleev + periodic table (in most } \\
\text { countries periodic table is not used as eponym, so it disappears); } \\
\text { - single displacement: Charles + Gay-Lussac law } \rightarrow \text { Charles law + Gay-Lussac (the } \\
\text { eponym changes its name from one country to country, namely Gay-Lussac law in } \\
\text { Belarusian tradition of teaching physics is Charles law in US usage); } \\
\text { - double displacement: Claisen reaction + Wurtz adapter } \rightarrow \text { Claisen adapter + Wurtz } \\
\text { reaction (although the process is quite speculative, all the four eponyms actually exist). }\end{array}$ \\
\hline
\end{tabular}

The described resemblance between real and educational Universes, formation of chemical bonds and eponyms, chemical compounds and scientific eponyms in their nomenclature and transformations raises a bunch of questions. Is it OK to extrapolate patterns identified here onto practical science education? How productive can it be for science education? What are other components of educational Universe? Figuratively speaking, is our educational Universe expanding or shrinking? If eponym is a crystal of linguistic human-substance synthesis in the fields of humanization and historicism, what are other crystals initiated by other didactic principles? Research on such polyhedral, looking theoretical but essentially very hands-on educational issues is worth pursuing and stays always welcome on the pages of Journal of Baltic Science Education. 